Terr. Atmos. Ocean. Sci., Vol. 18, No. 5, 923-950, December 2007

\title{
Influence of Lightning on the Observation of Seismic Electromagnetic Wave Anomalies
}

\author{
Jun Izutsu ${ }^{1, *}$
}

(Manuscript received 11 May 2006, in final form 4 June 2007)

\begin{abstract}
For two decades, many researchers have been claiming that pre-seismic electromagnetic phenomena may be useful in short-term earthquake prediction. Despite much effort, however, the relationship between anomalous electromagnetic signals and earthquakes has not been proven. In this paper, we examine LF- and VLF-range electromagnetic-pulse data accumulated by Kyoto University since 1981, with special emphasis on the influence of lightning. Our data on electromagnetic pulses were compared with available lightning data to evaluate the influence of lightning.

We examined how far lightning affects our observation system. Although maximum distance varies with time and frequency ranges, it was found our observation system is influenced by lightning as far away as about $250 \mathrm{~km}$ in the $L F$ range and about $420 \mathrm{~km}$ in the VLF range. The alleged "seismic" electromagnetic signals, which were reported in previous studies, were then re-examined with the view that lightning in the above ranges could be a source of noise.

An increase in the number of the electromagnetic pulses was observed 50 minutes before the 17 January 1995 Hyogo-ken Nanbu earthquake. We analyzed the continuous VLF electromagnetic waveforms at that time. We classified the waveforms and compared them with the lightning data and searched for the origin of each waveform. Most of the waveforms were explained by lightning activities.

Moreover, in the cases of other earthquakes, the observed electromagnetic pulse anomalies may be considered as due to lightning. For the obser-

\footnotetext{
${ }^{1}$ Earth Watch - Safety Net Research Center, Chubu University, Aichi, Japan

* Corresponding author address: Dr. Jun Izutsu, Earth Watch - Safety Net Research Center, Chubu University, Aichi, Japan; E-mail: izutsu@isc.chubu.ac.jp doi: 10.3319/TAO.2007.18.5.923(T)
} 


\begin{abstract}
vation of electromagnetic pulses in LF and VLF ranges, the application of electromagnetic pulse anomalies to earthquake forecast requires a good deal more effort to achieve convincible results and cannot be considered promising.
\end{abstract}

\title{
(Key words: Seismo-electromagnetic phenomena, VLF electromagnetic wave, Lightning)
}

\section{INTRODUCTION}

Since seismology started, prediction of earthquakes has always been an important research subject. Substantial effort over many years has led to considerable progress being made in the field of long-term prediction. We can estimate the possible occurrence of earthquakes and their damage on a time scale of several years to decades. However, despite its extreme importance, practical short-term earthquake prediction, on a time scale of hours to days, still remains allusive. During the last two decades, however, many researchers have been claiming that pre-seismic electromagnetic phenomena may be useful for short-term prediction.

Much research has been conducted on pre-seismic electromagnetic signals in various frequency ranges [DC range (VAN method): Varotsos et al. (1984a, b) and Uyeda et al. (2000, 2002), ULF range: Fraser-Smith et al. (1990), Molchanov et al. (1992), and Kopytenko et al. (1993), ELF range: Maki and Ogawa (1983) and Hata (1997), VLF range: Gokhberg et al. $(1979,1982)$, Yoshino et al. (1985, 1997), and Yamada and Oike (1996), LF range: Oike and Ogawa (1986) and Yamada and Oike (1996), HF range: Warwick et al. (1982), Maeda and Tokimasa (1996), and Enomoto et al. (1997)].

Almost all of these reports only showed temporal correlations between "seismic" electromagnetic signals and the occurrence of earthquakes. Though, Yoshino et al. (1985), Asada et al. (2001), and Hattori (2004) detected that signals came from epicentral areas.

The relationship between these anomalous electromagnetic signals and earthquakes, however, has not been proven and the nature of such signals is still not clear due to insufficient observation data and theoretical background.

It seems that there are the following two basic unsolved problems in general. The first problem is the difference in the characteristics of electromagnetic radiation observed in the field and in the laboratory. Actually, electromagnetic emission associated with rock fracture is a well known phenomenon (e.g., Yoshida and Ogawa 2004). Some mechanisms of electromagnetic radiation, such as the piezoelectric effect and electrokinetic effect, are suggested (Nitsan 1977; Ishido and Mizutani 1981; Ogawa et al. 1985; Cress et al. 1987; Yoshida et al. 1997). According to these laboratory experiments, it is expected that the largest electromagnetic radiation should be observed at the time of an earthquake when the largest stress change occurs. However, no electromagnetic signal has been confirmed at the origin times of earthquakes.

The second one is the attenuation problem. Generally speaking, electromagnetic signals cannot penetrate the earth's crust deeply, and vice versa, the electromagnetic signals which are generated at depth cannot reach the earth's surface ("Skin depth" effect). When the conductivity 
of the earth's crust is taken to be $10^{-4} \mathrm{~S} \mathrm{~m}^{-1}$ (a typical value for dry granite), permittivity is $4 \times 10^{-11}\left(=5 \times \varepsilon_{0}\right) \mathrm{F} \mathrm{m}^{-1}$, magnetic permeability is $4 \pi \times 10^{-7} \mathrm{H} \mathrm{m}^{-1}$ and the frequency of incident electromagnetic waves is $1 \mathrm{kHz}$, the skin depth is about $1.6 \mathrm{~km}$. The skin depth is in inverse proportion to the square root of the conductivity and the frequency. Thus, lower frequency electromagnetic waves have more possibilities of reaching the earth's surface.

Because of these two serious problems, we are not certain that the observed "so called" seismic electromagnetic signals were truly causally related with earthquakes.

In this paper, we examine data of electromagnetic radiation, accumulated by Kyoto University over many years, in the LF and VLF ranges and discuss whether or not what the observation system observed was truly causally related with earthquakes.

\section{REVIEW OF PREVIOUS STUDIES CONDUCTED AT KYOTO UNIVERSITY}

At Kyoto University, "seismic" electromagnetic signals have been investigated since 1981. After preliminary observations, continuous observations of electromagnetic pulses in the LF range $(163 \mathrm{kHz}$, since 1983) and VLF range $(1-20 \mathrm{kHz}$, since 1987) have been conducted. The observation system was installed at Uji station, Kyoto, Japan. The results of the observations were reported by Oike and Ogawa (1986), Oike and Murakami (1993), Oike et al. (1993), Oike and Yamada (1994), Yamada and Oike (1996), and Yamada (1998). In this section, we briefly review the results of these studies and point out some inherent problems.

Figure 1a is a block diagram of the observation system. The LF range sub-system uses a radio receiver with a rod antenna as a sensor. A frequency of $163 \mathrm{kHz}$ was chosen for the observation. The AGC (Auto Gain Control) output of the receiver was amplified. The number of amplified pulses with amplitude greater than a fixed threshold level was counted (Fig. 1b). The counter could not separately count the successive pulses with intervals less than about 0.5 milliseconds.

The VLF range sub-system uses a ball antenna as a sensor. It was a hollow metal ball with a diameter of about $15 \mathrm{~cm}$ attached at the top of an 8-meter high insulated pole (Ogawa et al. 1966; Ogawa and Tanaka 1970; Ogawa 1973). It measured the vertical electric field between the ball and the ground. The number of amplified pulses with amplitude exceeding a fixed threshold was counted and recorded. In this system, continuous waveform of the VLF pulses also could be observed as audio signals. Just before and after the 1995 Hyogo-ken Nanbu earthquake, continuous waveform data of VLF electromagnetic pulses existed. This waveform data will be further discussed in detail in section 4.1.

Remarkable increase in the number of LF electromagnetic pulses was observed at Uji station several days before large earthquakes such as the 1984 Western Nagano Prefecture earthquake (Oike and Ogawa 1986). Oike and Murakami (1993) investigated the correlation between the observed number of pulses and the occurrence of 10 shallow earthquakes with $\mathrm{M}$ equal to or larger than 6, which occurred inland or under shallow sea with a water depth of $1000 \mathrm{~m}$ or less near Japan during the period from 1983 to 1991. Figure 2 shows the variation of the LF pulses obtained by stacking the observations after lining them up with respect to the origin time of each earthquake. The LF pulses start to increase at about three days before the 
origin time and decrease just before the origin time. Two peaks are seen two days before and six days after the origin time. Similar variation in LF pulses was also seen in the case of the 1993 Hokkaido-Nansei-Oki earthquake (M 7.8) of 12 July 1993 [Fig.13 in Oike and Yamada (1994)].

9 January 1995, eight days before the Hyogo-ken Nanbu earthquake, an increase in the number of the electromagnetic pulses was observed in both of the LF and VLF ranges [Fig. 2 in Yamada and Oike (1996)]. The variation of the pulses before and after the earthquake was different from those observed at other earthquakes (Fig. 2). Moreover, another increase in the pulses started 50 minutes before the earthquake [Fig. 5 in Yamada and Oike (1996)].

However, these authors did not present quantitative accounts on the "remarkable increase" in these reports. Another problem in their works is that there is a peak of the LF pulses six days after the origin time (Fig. 2), but this peak was left untouched without any attempt to explain it. This peak may have some significance in the general interpretation of the observation as will be mentioned later (section 4.2).

The influence of lightning on electromagnetic observation is actually very large. Oike et al. (1993) compared their data of the observed number of electromagnetic pulses with lightning data near Uji station and they reported that the increase in the number of pulses was correlated with lightning near Uji station. However, comparison between the observed pulses and far away lightning was not examined at that time. Yamada and Oike (1999) found that there was thunderbolt activity on 9 January 1995 from lightning data in the Kinki region. The lightning was observed at Hamada Weather Station in Shimane Prefecture 50 minutes before the earthquake. He suggested the possibility that the influence of lightning was significant in the observed increase of pulses just before the 1995 Hyogo-ken Nanbu earthquake.

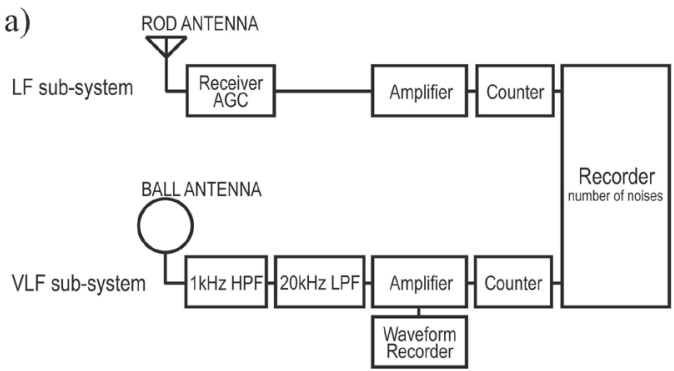

b)

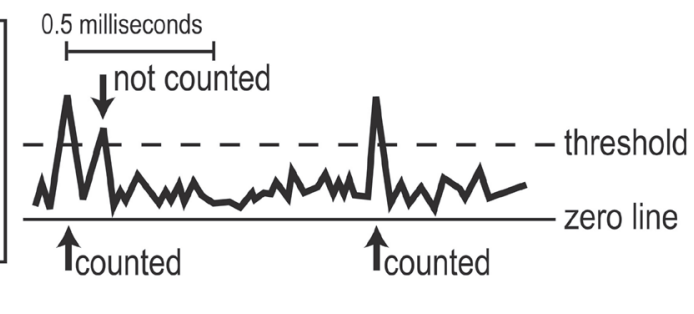

Fig. 1. (a) The block diagram of the observation system. The LF sub-system and VLF sub-system are unified [Oike and Ogawa (1986), Yamada (1998), edited]. (b) The sketch of the system of the counter. If an amplified input exceeds a fixed threshold level, it will be counted as a pulse. This counter cannot separately count the successive pulses occurring with interval less than 0.5 milliseconds. 


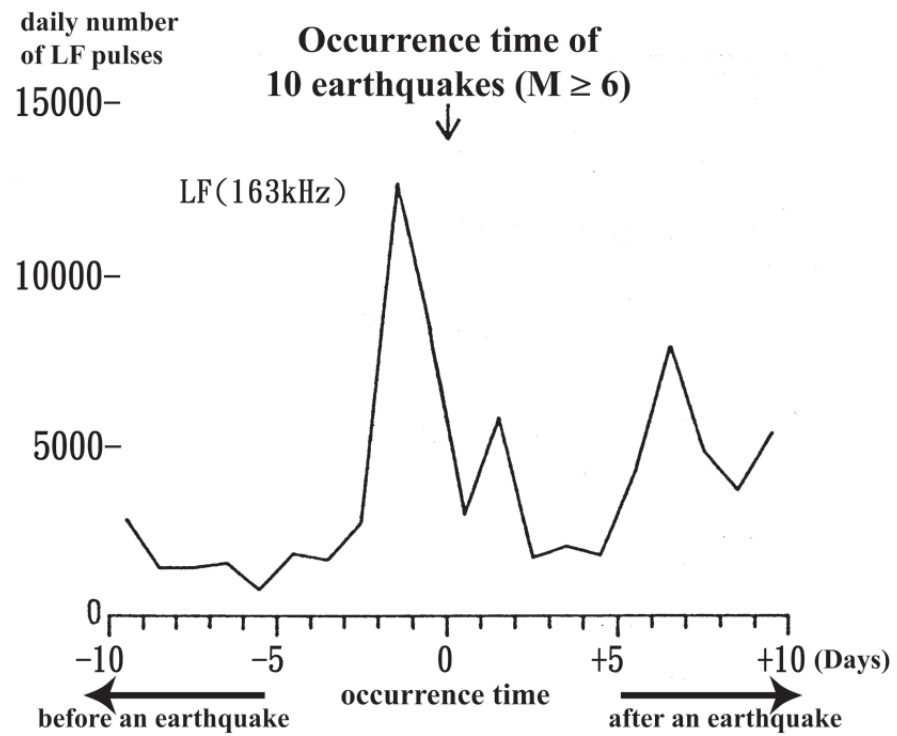

Fig. 2. The general tendency of the variation of the daily number of LF pulses 10 days before and 10 days after earthquakes. This figure was made by stacking variations of the number of LF pulses observed before and after 10 earthquakes with $\mathrm{M}$ equal to or larger than 6 with centering at the occurrence time of earthquakes [Oike and Murakami (1993), Oike and Yamada (1994), edited].

\section{RELATIONSHIP BETWEEN THE ELECTROMAGNETIC PULSE ANOMALIES AND LIGHTNING}

\subsection{LF and VLF Observation Network in the Tokai and Kanto Regions}

The previous studies included only one observation station, i.e., Uji station in Kyoto. After the 1995 Hyogo-ken Nanbu earthquake, RIKEN initiated the International Frontier Research Program on Earthquakes in October, 1996. This program was aimed at basic research for earthquake prediction by utilizing electromagnetic methods (e.g., earth current) (Uyeda et al. 2000, 2002, 2004; Nagao et al. 2000). Our observation system was adopted in this program and several observation systems were installed in the Tokai and Kanto regions. Figure 3 shows the list of observation stations and their distribution. Observation stations, except Kyoto (KYT), are basically earth current observation stations of the RIKEN project, and the data for LF and VLF pulses were recorded at 10-second sampling and telemetered to Tokai University. The five-year RIKEN International Frontier Research Program on Earthquakes was terminated on March, 2002 and most of the observation stations were accordingly closed. 


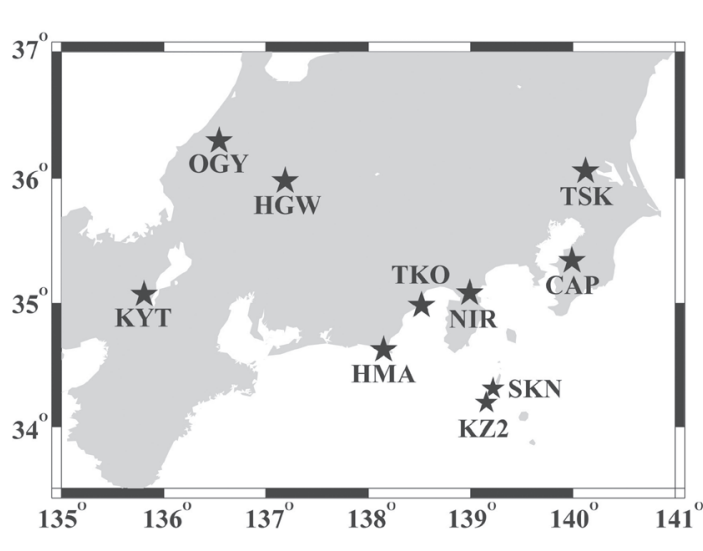

\begin{tabular}{|c|c|c|c|c|}
\hline & latitude & longitude & Range & Note \\
\hline $\begin{array}{c}\text { Kyoto } \\
\text { (KYT) }\end{array}$ & $35.0292^{\circ}$ & $135.7828^{\circ}$ & VLF,LF & $\begin{array}{c}\text { On the roof of a building in Kyoto Univ. } \\
\text { Radio audio is observed in VLF range. }\end{array}$ \\
\hline $\begin{array}{c}\text { Ogoya } \\
\text { (OGY) }\end{array}$ & $36.2969^{\circ}$ & $136.5409^{\circ}$ & VLF,LF & \\
\hline $\begin{array}{c}\text { Hagiwara } \\
\text { (HGW) }\end{array}$ & $35.9812^{\circ}$ & $137.1883^{\circ}$ & LF & \\
\hline $\begin{array}{c}\text { Hamaoka } \\
\text { (HMA) }\end{array}$ & $34.6258^{\circ}$ & $138.1490^{\circ}$ & LF & \\
\hline $\begin{array}{c}\text { Shimizu } \\
\text { (TKO) }\end{array}$ & $34.9846^{\circ}$ & $138.5196^{\circ}$ & VLF,LF & On the roof of a building in Tokai Univ. \\
\hline $\begin{array}{c}\text { Nirayama } \\
\text { (NIR) }\end{array}$ & $35.0852^{\circ}$ & $138.9918^{\circ}$ & VLF,LF & \\
\hline $\begin{array}{c}\text { Kozu Is. } \\
\text { (KZ2) }\end{array}$ & $34.1995^{\circ}$ & $139.1545^{\circ}$ & VLF,LF & Crashed by the landslide on July 4, 2000. \\
\hline $\begin{array}{c}\text { Kisarazu } \\
\text { (CA) }\end{array}$ & $35.3442^{\circ}$ & $139.9933^{\circ}$ & VLF,LF & Radio audio is observed in VLF range. \\
\hline $\begin{array}{c}\text { Tsukuba } \\
\text { (TSK) }\end{array}$ & $36.0571^{\circ}$ & $140.1263^{\circ}$ & VLF,LF & Radio audio is observed in VLF range. \\
\hline $\begin{array}{c}\text { Shikine Is. } \\
\text { (SKN) }\end{array}$ & $34.3347^{\circ}$ & $139.2100^{\circ}$ & VLF,LF & $\begin{array}{c}\text { Moved from KZ2 on July 19, 2000. } \\
\text { Affected strongly by the LORAN-C. }\end{array}$ \\
\hline
\end{tabular}

Fig. 3. The distribution of the observation stations.

According to the previous studies, increase in LF pulses began to be observed from three days before earthquakes (Fig. 2) (Oike and Murakami 1993). For comparison with previous studies, similar analysis was performed in this study.

Figure 4 (left) is the list of earthquakes of $\mathrm{M}_{\mathrm{JMA}}$ equal to or larger than 6 which occurred with a depth of $30 \mathrm{~km}$ or less in Japan and earthquakes of $\mathrm{M}_{\mathrm{JMA}} 5$ or more which occurred with a depth of $30 \mathrm{~km}$ or less near the observation network $\left[32-38^{\circ} \mathrm{N}, 134-142^{\circ} \mathrm{E}\right.$, the rectangle shown in Fig. 4 (right)] from April, 1997 to March, 2002. Earthquakes which occurred in the sea area with water depth of $1000 \mathrm{~m}$ or more were excluded. Aftershocks and the Izu Islands earthquake swarm accompanying the eruption of Miyake Island in 2000 are also excluded. It is shown in the column "anomaly" in Fig. 4 (left) whether or not the number of LF pulses increased within 3 days before earthquakes at the observation station nearest to the epicenter. The epicentral distance to the nearest station is also shown in Fig. 4 (left). Because the absolute criterion of: "increase of the number of pulses" was not given in Oike and Murakami (1993), we also judged the increase by eye. Out of 20 earthquakes, the increase was barely recognized for 7 events. In the distribution map of earthquakes [Fig. 4 (right)], these earthquakes are depicted by solid circles. Figure 5 shows the variation in the LF pulses obtained by stacking the 7 observations after lining them up with respect to the origin time of each earthquake in the same way as Fig. 2.

It may be observed that the features are different from the result of Oike and Murakami (1993) in Fig. 2 in several aspects. Figure 2 has two peaks on two days before and six days after the earthquake, whereas Fig. 5 has three peaks on eight days before, three days before and nine days after the earthquake. However, these results have a common tendency of increase a few days before an earthquake, and decrease near the earthquake occurrence day. Moreover, it seems that they both have a 5- to 8-day cycle. The possible significance of this cycle will be mentioned later (section 4.2). 


\begin{tabular}{|c|c|c|c|c|c|c|c|}
\hline $\begin{array}{l}\text { Origin Time (Local Time) } \\
\text { (vear mon day hour mins) }\end{array}$ & \begin{tabular}{|l|} 
latitude \\
(degree) \\
\end{tabular} & 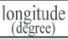 & $\begin{array}{l}\text { depph } \\
\text { (km) }\end{array}$ & $\mathrm{M}_{\mathrm{s}}$ & location & $\begin{array}{c}\text { nearest station } \\
\text { (epicentral distance) }\end{array}$ & anomaly \\
\hline $\begin{array}{lllll}997 & 05 & 13 & 14 & 38\end{array}$ & 31.945 & 130.305 & 9.2 & 6.4 & N W Kagoshima & KYT (61km) & \\
\hline $199705 \quad 2208 \quad 11$ & 34.226 & 139.225 & 0.0 & 5.2 & Near Niijima & $\mathrm{KZ2}(7 \mathrm{~km})$ & \\
\hline $\begin{array}{lllll}1997 & 05 & 24 & 02 & 50\end{array}$ & \begin{tabular}{|l|}
44.497 \\
\end{tabular} & 137.503 & 23.1 & 6.0 & Ensyunada & HMA $(61 \mathrm{~km})$ & YES \\
\hline $\begin{array}{lllll}1997 & 06 & 25 & 18 & 50\end{array}$ & 34.438 & 131.669 & 8.3 & 6.6 & Yamaguchi & KYT $(385 \mathrm{~km})$ & \\
\hline 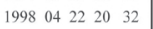 & 35.165 & 136.570 & 10.5 & 5.5 & Shiga Gifu Border & KYT (70km) & \\
\hline 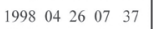 & 34.960 & 139.177 & 6.1 & 5.0 & E Off Izu Peninsula & NIR $(22 \mathrm{~km})$ & \\
\hline $19980503 \quad 1109$ & 34.957 & 139.179 & 4.7 & 5.9 & E Off Tru Peninsula & $\operatorname{NIR}(22 \mathrm{~km})$ & \\
\hline 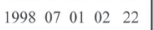 & 36.619 & 137.918 & 8.8 & 5.0 & Northern Nagano & $\mathrm{HGW}(96 \mathrm{~km})$ & YES \\
\hline $\begin{array}{lllll}1998 & 08 & 12 & 15 & 13\end{array}$ & 36.234 & 137.631 & 2.8 & 5.0 & Hida Mountains & HGW (49km) & YES \\
\hline $\begin{array}{lllll}1998 & 08 & 16 & 03 & 31\end{array}$ & 36.325 & 137.629 & 3.2 & 5.6 & Hida Mountains & HGW $(55 \mathrm{~km})$ & YES \\
\hline 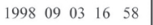 & \begin{tabular}{|l|l|}
39.803 \\
\end{tabular} & 140.905 & 7.9 & 6.2 & Northern Iwate & TSK $(421 \mathrm{~km})$ & \\
\hline $\begin{array}{lllll}1999 & 03 & 14 & 09 & 14\end{array}$ & 34.233 & 139.141 & 9.2 & 5.1 & Near Niijima & $\mathrm{KZ2}(4 \mathrm{~km})$ & YES \\
\hline $\begin{array}{lllll}1999 & 03 & 16 & 16 & 43\end{array}$ & 35.274 & 135.934 & 11.6 & 5.2 & N W Shiga & KYT (25km) & YES \\
\hline $\begin{array}{lllll}1999 & 03 & 28 & 01 & 37\end{array}$ & \begin{tabular}{|c|}
34.096 \\
\end{tabular} & 139.010 & 14.0 & 5.2 & Near Niijima & KZ2 (18km) & YES \\
\hline 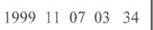 & 36.056 & 135.797 & 15.0 & 5.0 & N W Off Kinki & OGY $(72 \mathrm{~km})$ & \\
\hline $2000 \quad 06 \quad 0706 \quad 16$ & 36.823 & 135.566 & 21.3 & 6.2 & N W Off Hokuriku & $\mathrm{OGY}(105 \mathrm{~km})$ & \\
\hline $\begin{array}{lllll}2000 & 10 & 06 & 13 & 30\end{array}$ & 35.271 & 133.352 & 9.0 & 7.3 & Western Tottori & KYT $(224 \mathrm{~km})$ & \\
\hline $\begin{array}{lllll}2001 & 01 & 04 & 15 & 18\end{array}$ & 36.953 & 138.772 & 11.2 & 5.3 & Mid Niigata & TSK $(157 \mathrm{~km})$ & \\
\hline $\begin{array}{lllll}2001 & 03 & 31 & 06 & 09\end{array}$ & 36.819 & 139.378 & 4.7 & 5.2 & N W Gunma & TSK $(108 \mathrm{~km})$ & \\
\hline $200108 \quad 25 \quad 22 \quad 21$ & 35.149 & 135.663 & 8.2 & 5.4 & Mid Kyoto & KYT $(16 \mathrm{~km})$ & \\
\hline
\end{tabular}

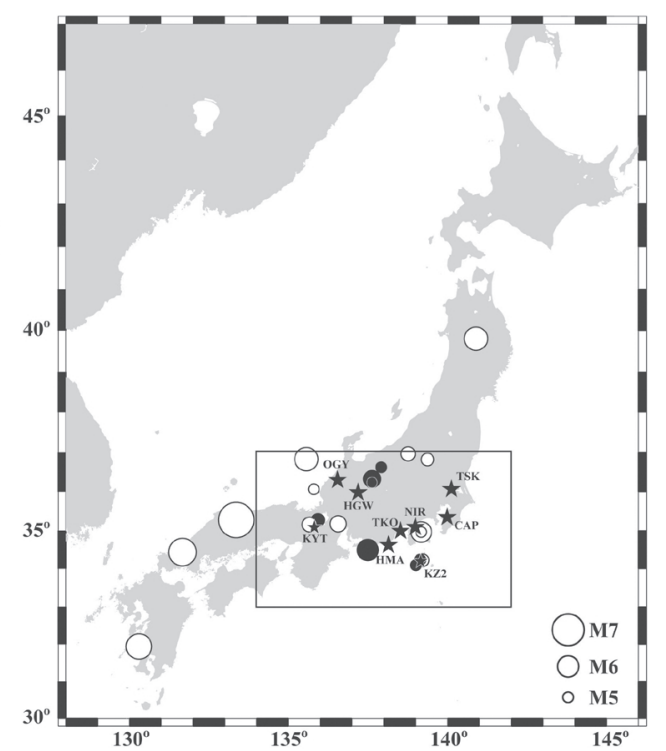

Fig. 4. The list of earthqaukes which are used for analysis and the distribution of earthquakes. A closed circle shows the epicenter of the earthquake which was accompanied by an increase of LF pulses within three days before the earthquake.

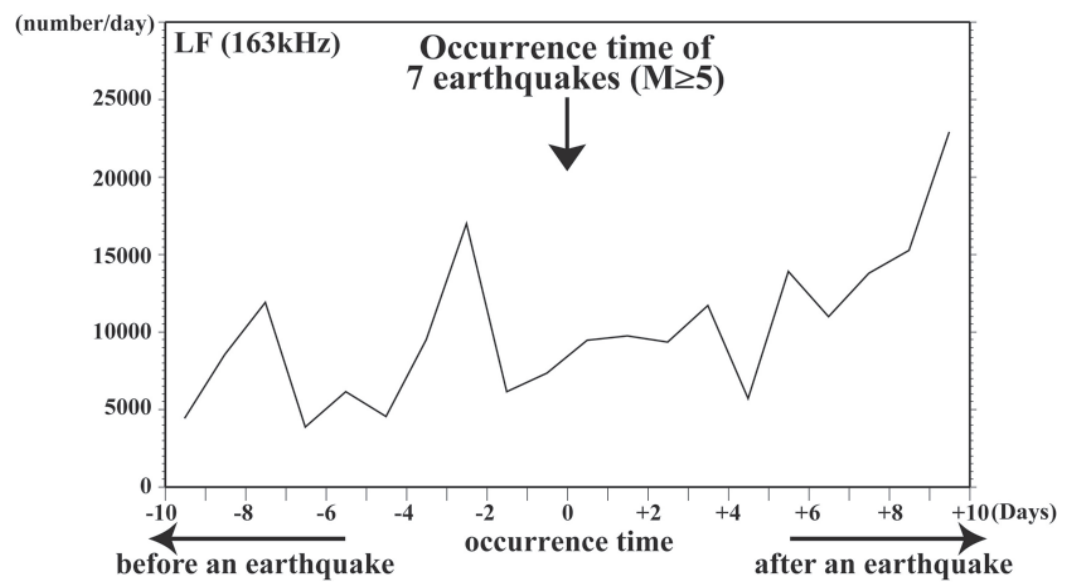

Fig. 5. The variation of the daily number of LF pulses 10 days before and 10 days after earthquakes. This figure was made by the stacking of variations in the number of LF pulses observed before and after 7 earthquakes (shown in Fig. 4) with centering at the occurrence time of earthquakes. 


\subsection{Comparison of Observed Electromagnetic Pulses with Lightning Data}

Thunderbolt activity is the main source of natural electromagnetic noise in VLF and LF ranges. Since pulse-like electric current flows at the time of lightning, electromagnetic waves are produced in wide frequency ranges.

In Japan, each electric power company uses a lightning location system, such as LLP system and LPATS because the cloud-to-ground lightning often cause power failure (Shindo 1998). In addition, Franklin Japan Corporation built the Japan Lightning Detection Network (JLDN) and recorded lightning data in almost all of Japan. This data has been available since June 1999. The lightning data contain the time, location, polarity, and the current amplitude of the cloud-to-ground lightning. Figure 6 (left) shows the distribution pattern of lightning (plotted as black dots) detected by the JLDN during one year from June 1999. The lightning is too frequent (about 2.6 million data points collected in that year), so that only about one percent of data is plotted. Figure 6 (right) shows the histogram of the amplitude of the lightning current given in the lightning data from June, 1999 to March, 2001. The detection efficiency of JLDN is over $90 \%$ for the summer negative lightning with current intensity over $5 \mathrm{kA}$ and is $70 \%$ for the winter positive lightning which is more difficult to detect (Ishii et al. 2001).

We can estimate the influence of lightning on our pulse observing system by investigating which lightning is recorded in our system. Since the numbers for recorded lightning is far greater than the number of pulses we record, it may be assumed that our system records only stronger lightning noise. The strength, i.e., the amplitude of the electromagnetic pulse generated by lightning is proportional to the lightning current, $I(\mathrm{kA})$, and in inverse proportion to the distance, $D(\mathrm{~km})$, from the lightning location to observation station in the case of far (but within $1000 \mathrm{~km}$ ) lightning. To be exact, the amplitude is proportional to $1 / D^{3}$ (near field term), $1 / D^{2}$ (mid field term) and $1 / D$ (far field term). In this case, we focus on how far lightning affects our observation system. Therefore, we define a simple parameter $T=I / D$ for evaluating the importance of each lightning. Thus, it may be understood that our pulse observation system is recording lightning pulses with $T$-values exceeding some threshold, $T_{t}$.

First, we tentatively set a value for the threshold $T_{t}$ and exclude the lightning with $T$ less than $T_{t}$ from the lightning dataset, assuming the remaining lightning may correspond to the pulses recorded by our observation system. If all of what our observation systems record are lightning, the time series of the number of lightning with $T$ larger than $T_{t}$ and the time series of the number of recorded electromagnetic pulses would be identical when proper $T_{t}$ is chosen. This $T_{t}$ is the threshold defining the sensitivity of our observation system to lightning. In other words, it represents "the lightning detection ability" of our observation system. In order to search for a proper $T_{t}$, the correspondence of lightning data to our records of LF and VLF pulses is examined. For this purpose, variance reduction $(V r)$ between the two time series is calculated by:

$$
V r=\left\lfloor 1-\frac{\sum_{i}\left|f(i)-a \cdot g\left(i, T_{t}\right)\right|^{2}}{\sum_{i} f(i)^{2}}\right\rfloor \times 100,
$$


where $f(i)$ is the number per 10 seconds (determined by the 10-sec sampling rate) of observed pulses and $g\left(i, T_{t}\right)$ is the number per 10 seconds of lightning with $T$ larger than $T_{t}$, and $a$ is a constant. The variance reduction represents the fitting of $f(i)$ and $g\left(i, T_{t}\right)$. It is large when $f(i)$ and $g\left(i, T_{t}\right)$ have a good correlation. If all the pulses are of lightning origin and both time series are complete, $V r$, will be 100 with $a=1$. The adjusting factor $a$ is introduced to take care of the systematic disparity in the numbers of recorded events in the two observation systems. Some of the causes of disparity are as follows:

(1) Our observation system is sensitive to cloud-to-cloud lightning, whereas it is not recorded in the lightning data.

(2) In the LF range, our system gives small numbers of pulses because some lightning has little LF (163 kHz) component, whereas broad band records by the lightning monitoring do not show such a tendency.

(3) The lightning data doesn't cover areas out of the Japan region, whereas our system may be affected by lightning from a wider area.

(4) As stated above, we do approximate calculations using only the far field term.
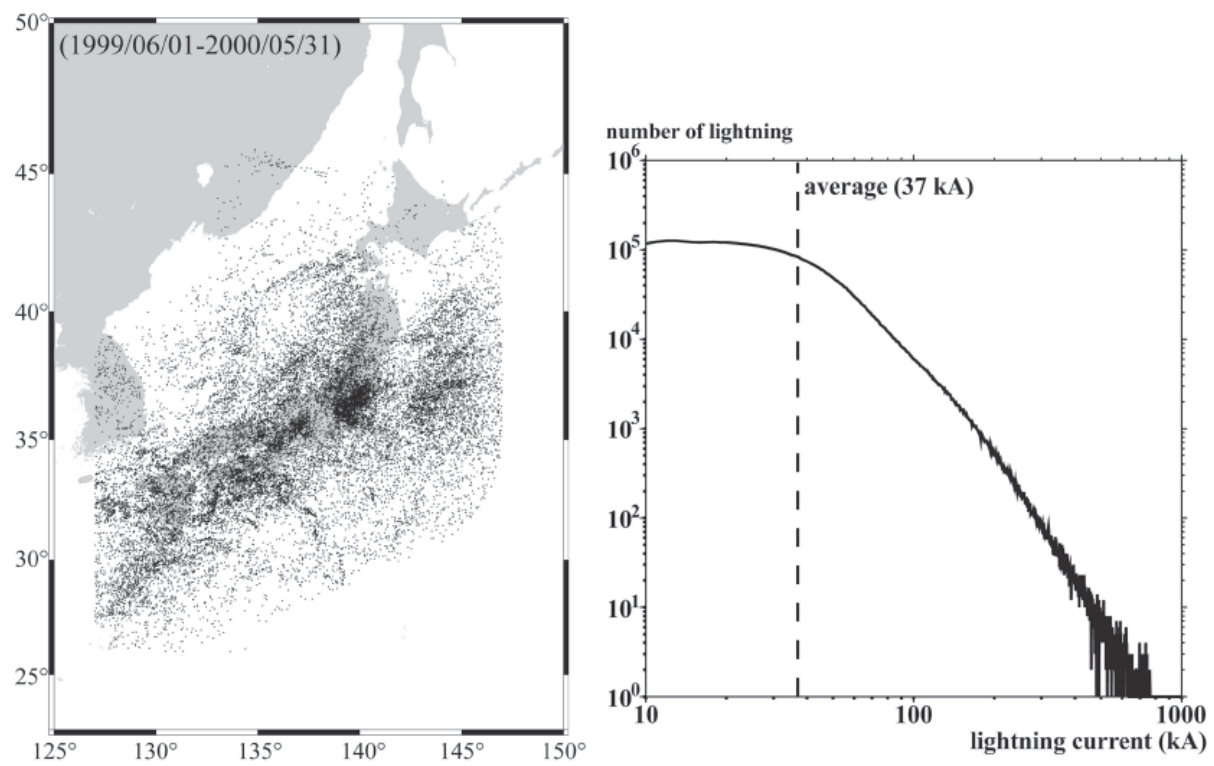

Fig. 6. (Left) The distribution of lightning around Japan. The black dots show the location of lightning during one year from June 1999. Lightning strikes are so great that only about one percent of data is plotted. (Right) The histogram of the amplitude of the lightning current given in the lightning data from June, 1999 to March, 2001. The average lightning current is about $37 \mathrm{kA}$. 
These problems of excess and deficiency of the lightning data relative to the pulse data are imposed on the constant $a$ [i.e., $a<1$ means an excess of lightning data (e.g., problem 2 ) and $a>1$ means a deficiency of lightning data (e.g., problem 1 and 3)]. $T_{t}$ and $a$ are varied and the variance reduction is calculated for various combinations of the values of $T_{t}$ and $a$ to seek the pair of $T_{t}$ and $a$ which gives the largest value of the variance reduction, $V r$.

Since propagation situations are different between daytime and nighttime, the best pair of $T_{t}$ and $a$ is also different between daytime and nighttime.

Variance reduction is normalized by the number of observed pulses. Thus, when the number of observed pulses is small, a small difference between the number of lightning and recorded pulses makes a large reduction in the variance reduction. As a matter of fact, the highest variance reduction is very small (under 10 in many cases) in winter when there is less lightning around Japan. Thus, we use the data in summer.

\subsection{Result}

Figure 7 shows the data for August, 1999. In the upper panel, the number of signals per 10 seconds is depicted. The red signal means the number of all lightning all around Japan given in the company's lightning data, while the black signal means the number at $T_{t}$ (daytime: 0.1, nighttime: 0.08 ) and $a$ (daytime: 1.3, nighttime: 1.1 ) in the case of Kozu Island station (KZ2). The lower panel shows the number per 10 seconds of VLF pulses recorded at KZ2. The highest variance reduction $(V r)$ is 45.2 in the daytime and 80.8 in the nighttime with these pairs of $T_{t}$ and $a$. The number of lightning all around Japan shown in red has a general tendency similar to the number of VLF pulses. Thus, the qualitative correspondence between the lightning and observed pulses is clearly shown. The number of lightning at the best $T_{t}$ and $a$ shown in black has a nearly one-to-one correspondence to the number of VLF pulses. Thus, the quantitative correspondence is also shown.

In the case of LF pulses, similarly, Fig. 8 shows the data for July, 2000. In the upper panel, the number of signals per 10 seconds is depicted. The red signal indicates the number for all lightning around Japan, while the black signal indicates the one at $T_{t}$ (daytime: 0.17 , nighttime: 0.133 ) and $a$ (daytime: 0.55 , nighttime: 0.5 ) in the case of Hamaoka station (HMA). The lower panel shows the number per 10 seconds of LF pulses recorded at HMA. The highest variance reduction $(V r)$ is 61.6 in the daytime and 46.8 in the nighttime with these pairs of $T_{t}$ and $a$.

Although the sensitivity to lightning (or "detection ability") differs with observation stations, we used, for simplicity, the common value of $T_{t}$ as mentioned above and calculated the rough values of the sensitivity (or detection hereafter) range, $D$, by the equation $T=I / D$. Since the average value of the lightning current, $I$, is about $37 \mathrm{kA}$ (calculated from the lightning data from June, 1999 to March, 2001), the detection range is obtained as $463 \mathrm{~km}$ (VLF nighttime), $370 \mathrm{~km}$ (VLF daytime), $278 \mathrm{~km}$ (LF nighttime), and $218 \mathrm{~km}$ (LF daytime). The lightning generated within this range is recorded by our observation systems and affects our observations as electromagnetic pulses.

Figure 9 shows the detection range of lightning in the case of Uji station. Figure 6 (right) shows that there are a number of lightning which exceed $100 \mathrm{kA}$. Therefore, a lot of lightning out of this range is also recorded. 


\section{RELATIONSHIP BETWEEN ELECTROMAGNETIC PULSES AND EARTH- QUAKES (A CASE STUDY)}

\subsection{The 1995 Hyogo-Ken Nanbu Earthquake}

As mentioned in section 2, we observed two seismic electromagnetic anomalies in the case of the 1995 Hyogo-ken Nanbu earthquake. One is the increase in the number of electromagnetic pulses observed on 9 January 1995, eight days before the earthquake, and the other is the increase observed 50 minutes before the earthquake (Yamada and Oike 1996).

Nagao et al. (2002) compared the results of the observations of electromagnetic phenomena before and after the 1995 Hyogo-ken Nanbu earthquake reported by several researchers, including us, with the lightning data provided by all electric power companies in Japan. There was lightning activity on 9 January 1995 and it is suspected to have influenced observations [Fig. 1 in Nagao et al. (2002)]. Yamada and Oike (1999) also showed the influence of lightning on the observation at the same earthquake by using lightning data in the Kinki region. According
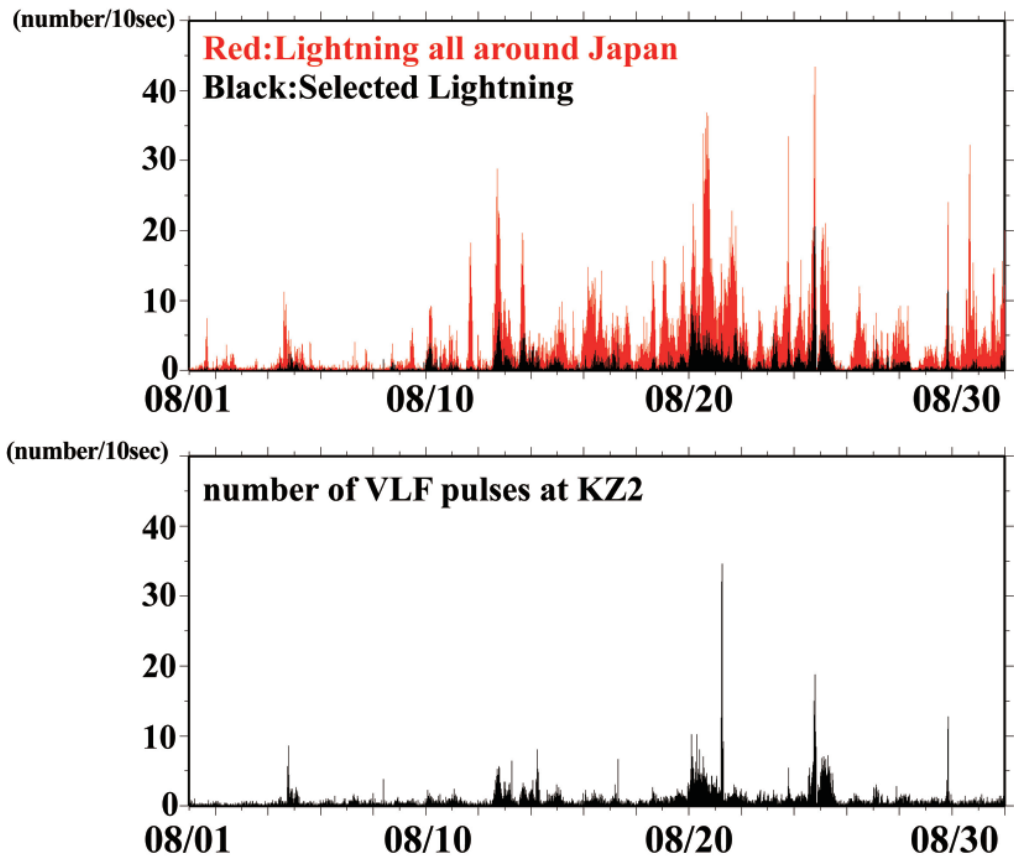

Fig. 7. The number per 10 seconds of lightning all around Japan (shown in red), the number per 10 seconds of lightning selected by $T_{t}$ (daytime: 0.1 , nighttime: 0.08 ) and $a$ (daytime: 1.3, nighttime: 1.1) (shown in black) and the number per 10 seconds of VLF pulses observed at KZ2 (Kozu Island). The data are for August, 1999. 

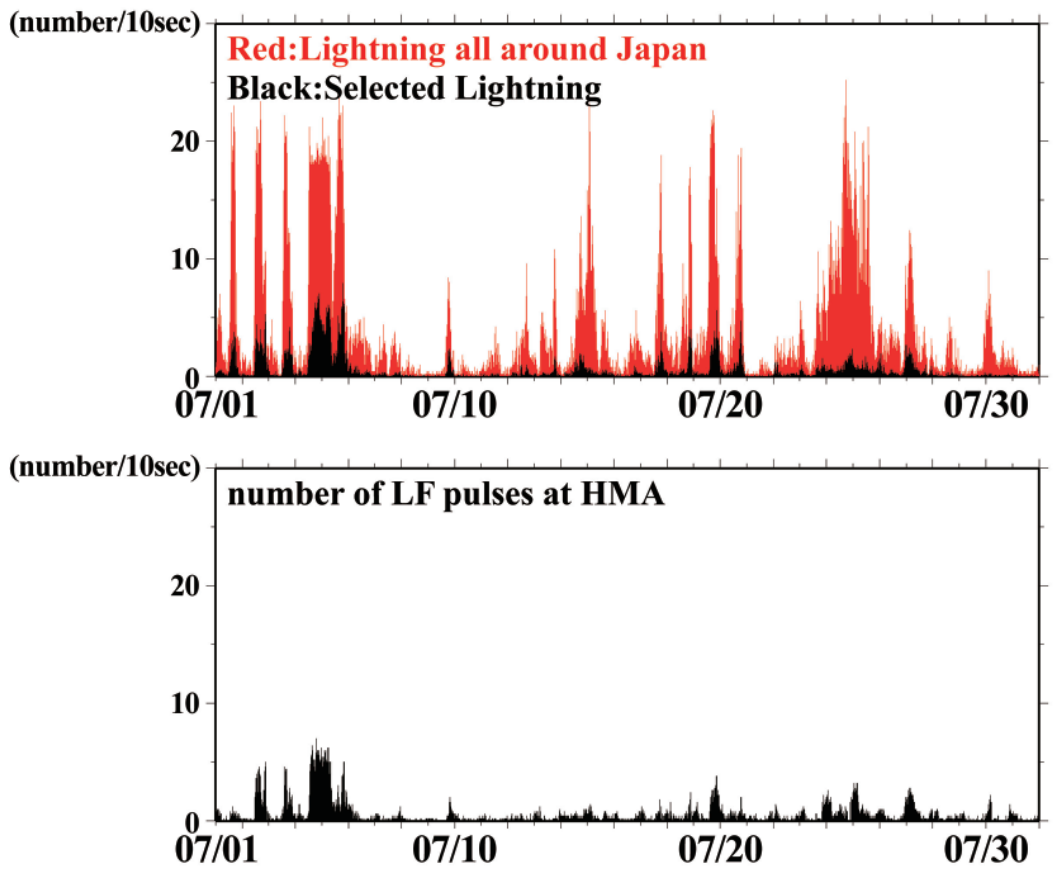

Fig. 8. The number per 10 seconds of lightning all around Japan (shown in red), the number per 10 seconds of lightning selected by $T_{t}$ (daytime: 0.17 , nighttime: 0.133 ) and $a$ (daytime: 0.55, nighttime: 0.5) (shown in black) and the number per 10 seconds of LF pulses observed at HMA (Hamaoka). The data are for July, 2000.

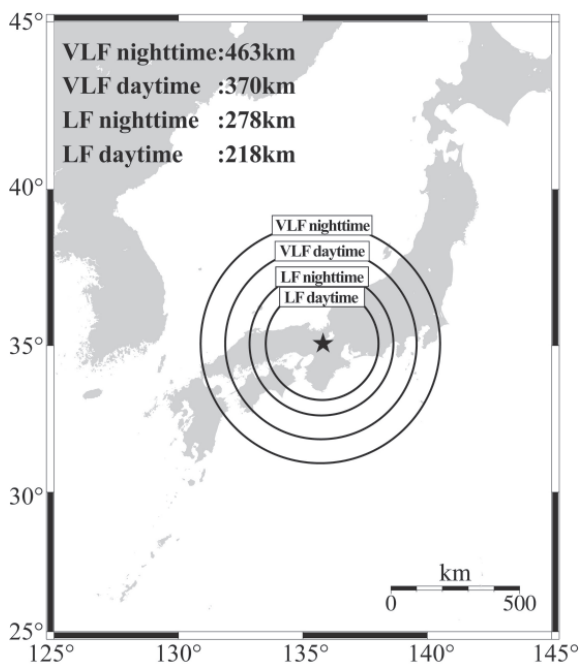

Fig. 9. Lightning detection ranges of this observation system for $\mathrm{Uji}$ station. Average lightning generated within these ranges will be observed and counted as an electromagnetic pulse. 
to the results of section 3, the lightning in the Kinki region certainly influences the observation system at Uji, supporting Nagao et al. (2002) and Yamada and Oike (1999). Since thunderstorms cause increases in the number of electromagnetic pulses, it seems difficult to affirm that the increase in the number of the electromagnetic pulses during this period was really related to the earthquake.

\subsubsection{The Waveform Analysis}

Another increase in the number of electromagnetic pulses was observed just before the Hyogo-ken Nanbu earthquake. During this period, continuous electric field waveforms of VLF pulses were recorded as audio signals by a video tape recorder. The waveforms were recorded from 04:50 to 10:03 on 17 January 1995 (local time). Since the origin time of the earthquake was $05: 46: 51$, it is a record from one hour before and four hours after the earthquake. These waveforms were shown in Yamada and Oike (1996) but the origins of the pulses were not fully analyzed. In Izutsu and Oike (2003), the origins of these pulses were investigated by a method used in the field of atmospherics.

According to the lightning data provided by Kansai Electric Power Co., Inc., there was no lightning in the Kinki region during this period. However, as mentioned in section 3, this observation would have been affected by far lightning also. Therefore, we examined the data of the lightning location systems of electric power companies. The electromagnetic pulses recorded simultaneously with lightning considered to be of lightening in origin. Although the available lightning data did not cover all the concerned region, thunderstorms were recorded for this period at least in Shimane Prefecture and off the coast of Kochi Prefecture (Fig. 16 as shown later). Continuous waveforms were recorded with a sampling rate of $500 \mathrm{kHz}$. The electromagnetic pulses with amplitude exceeding the threshold, set to eliminate the background noise, triggered the waveform recorder. Over 400 waveforms were picked up from the continuous record.

In atmospherics, waveforms are classified by their shapes, assuming dependence on their possible origins. We also classified observed waveforms into several types mainly based on previous studies (e.g., Kimpara 1956; Sao 1981) and investigated the origin of each type. We show, in the following, the results with figures of observed examples.

Ionospheric reflection type (Fig. 10): A large pulse appears first and then pulse-like peaks follow with almost constant interval. These peaks are considered to have been generated by multiple reflections between the earth and the ionosphere, and the difference in propagation path turns into the difference in arrival time (Fig. 10b). It is known that this type of waves is more often observed from near lightning than other types (Sao 1981). By using the time intervals of peaks, the propagation distances from the source can be calculated (Sao 1981). Figure 10c is the histogram of the calculated propagation distances of the ionospheric reflection type waveforms recorded in the morning of 17 January 1995. We found the nearest source of the waves was located at a distance of about $200-300 \mathrm{~km}$. This distance is comparable to the distance from the locations of lightning in Shimane Prefecture and off Kochi to the observation station. There was no waveform of this type with a propagation distance of $80 \mathrm{~km}$, which is the distance from the epicenter to the station. 
a) Ionospheric reflection type
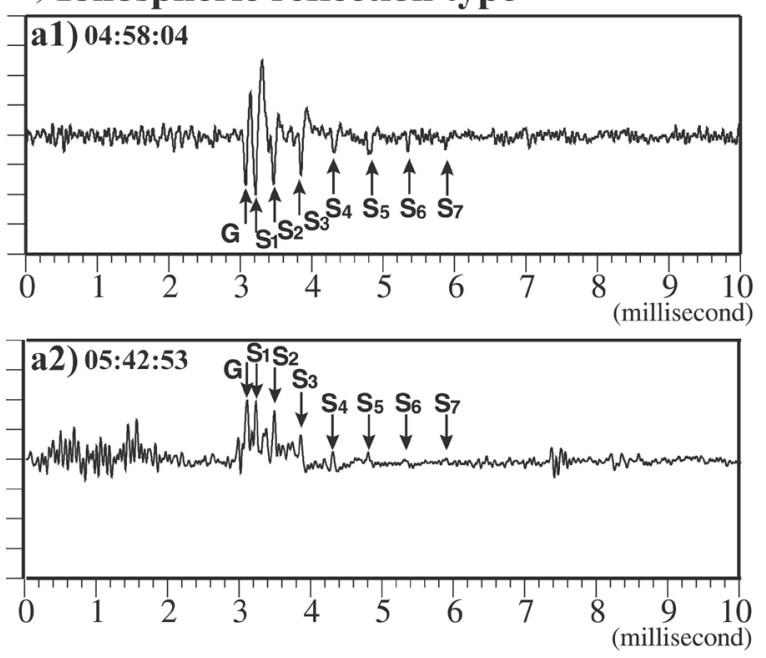

b)
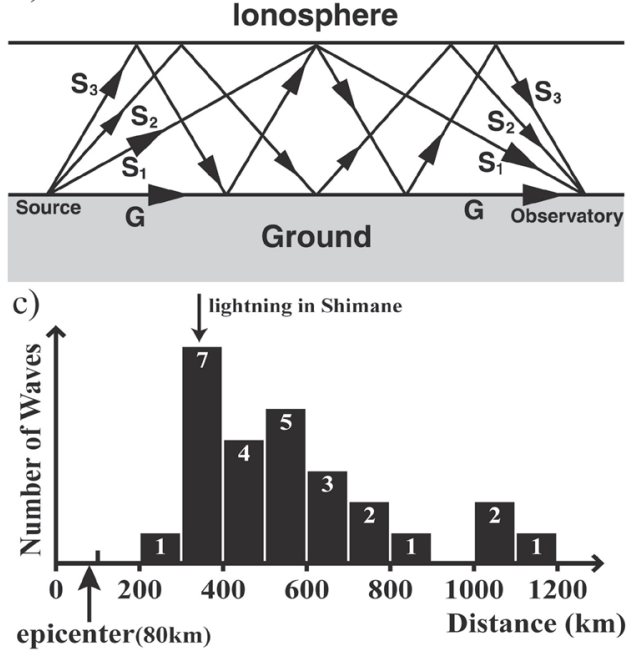

Fig. 10. (a) Examples of ionospheric reflection type waveform. Arrows show the peaks made from the multiple reflections between the earth and the ionosphere. They were observed at 04:58:04 and 05:42:53 and identified by comparison with lightning data, attributable to lightning. (b) The sketch of the multiple reflections between the earth and the ionosphere [Sao (1981), edited]. (c) The histogram of the propagation distance of ionospheric reflection type waveform. There was no waveform of ionospheric reflection type from the area around the epicenter.

Comparing with the lightning data, both waveforms shown in Figs. 10a1 and a2 were identified as generated by lightning. It was concluded that all the waveforms of this type were originated by lightning.

Dispersion type (Fig. 11): Waveforms showing dispersive character were classified to this type. This type was found to consist of three sub-types as shown in Figs. 11a, b, and c. All of these types indicate that they travel in the earth-ionosphere waveguide mode. In the frequency domain, there is a minimum in the power spectrum at about $1.6-1.8 \mathrm{kHz}$. This is interpreted as the cut-off frequency for the ionospheric height of $90 \mathrm{~km}$.

The classification of the three sub-types was made according to the ratio of PL and PH, where PL and PH stand for the maximum in the power spectrum below and above the cut-off frequency shown in Fig. 11. The three sub-types are quasi-sinusoidal type [PL is smaller than PH (Fig. 11a)], slow tail type [PL is larger than PH (Fig. 11b)] and intermediate type [PL is as large as PH (Fig. 11c)].

According to the studies of electromagnetic waves generated by lightning, their waveforms change with the propagation distance as illustrated in Fig. 12. The waveforms observed 
in near field show ionospheric reflection type. As the distance of propagation increases, they become intermediate type and finally quasi-sinusoidal type after propagating more than $3000 \mathrm{~km}$ (Schonland et al. 1940). In other words, a quasi-sinusoidal type wave was generated far away from the observation station, which is considered far beyond the detection range of earthquake related signals.

The slow tail type was demonstrated to be the zero-th mode wave of waveguide propagation and it was suggested to be the output of a pulse inputted over $1000 \mathrm{~km}$ away in the ELF range (Wait 1970). Hepburn (1957) showed that the slow tail type wave can be generated also when the electric pulse current is composed of components with frequencies under $1 \mathrm{kHz}$. Since our observed intermediate type also had a low frequency component (about $1 \mathrm{kHz}$ ), it was inferred that the intermediate type may also appear when the source electric pulse current had a lower frequency component.

Irregular high frequency type (Fig. 13): The waveform of this type is characterized by a high frequency component with about $10 \mathrm{kHz}$ superposed on the baseline, which often fluctuates irregularly during 1 - 5 milliseconds.

Checking with the lightning data, the irregular high frequency type was often found to occur just before lightning (one millisecond - one second before). The ionospheric reflection type waveform was observed about 60 milliseconds after the waveform shown in Fig. 13a and the intermediate type waveform was observed about 25 milliseconds after the waveform shown in Fig. 13b. Small amplitude and short period waveforms of irregular high frequency type occurred just before other waveforms as shown in Fig. 10a2. Irregular high frequency type

a) Quasi-sinusoidal type

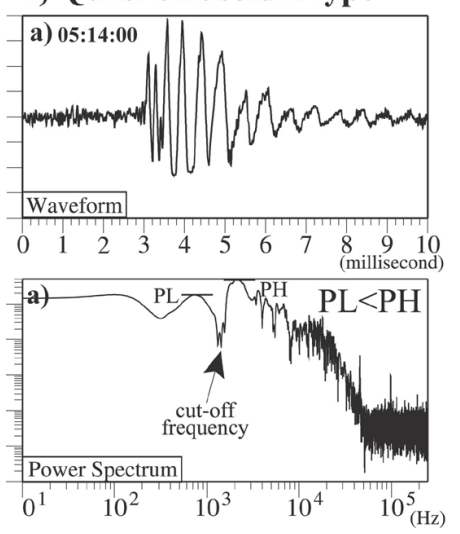

b) Slow tail type
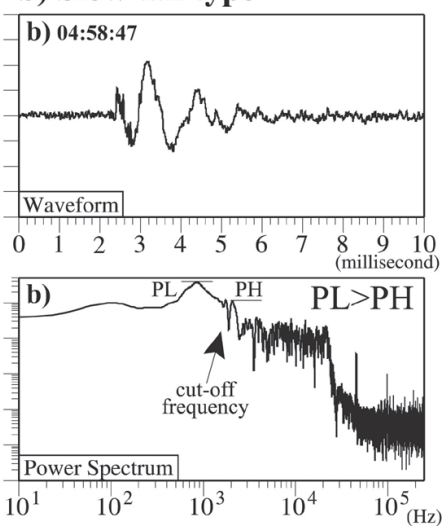

c) Intermediate type
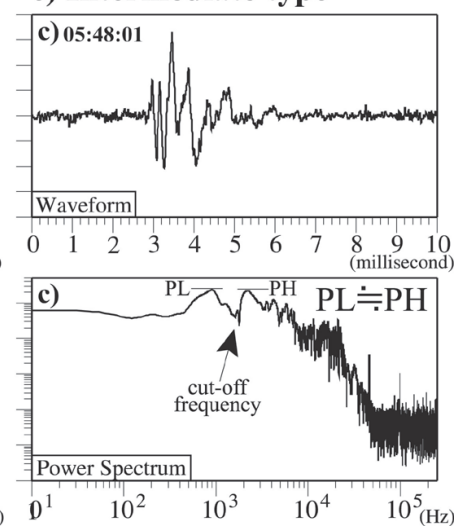

Fig. 11. Examples of observed waveforms and power spectrums of the dispersion type: (a) Quasi-sinusoidal type; (b) Slow tail type; and (c) Intermediate type. These pulses are waveguide mode waves between the earth and the ionosphere. The power spectrum has a minimum at the cut-off frequency (arrows). These three types were classified according to the ratio of PL and $\mathrm{PH}$, the maximal powers below and above the cut-off frequency. 


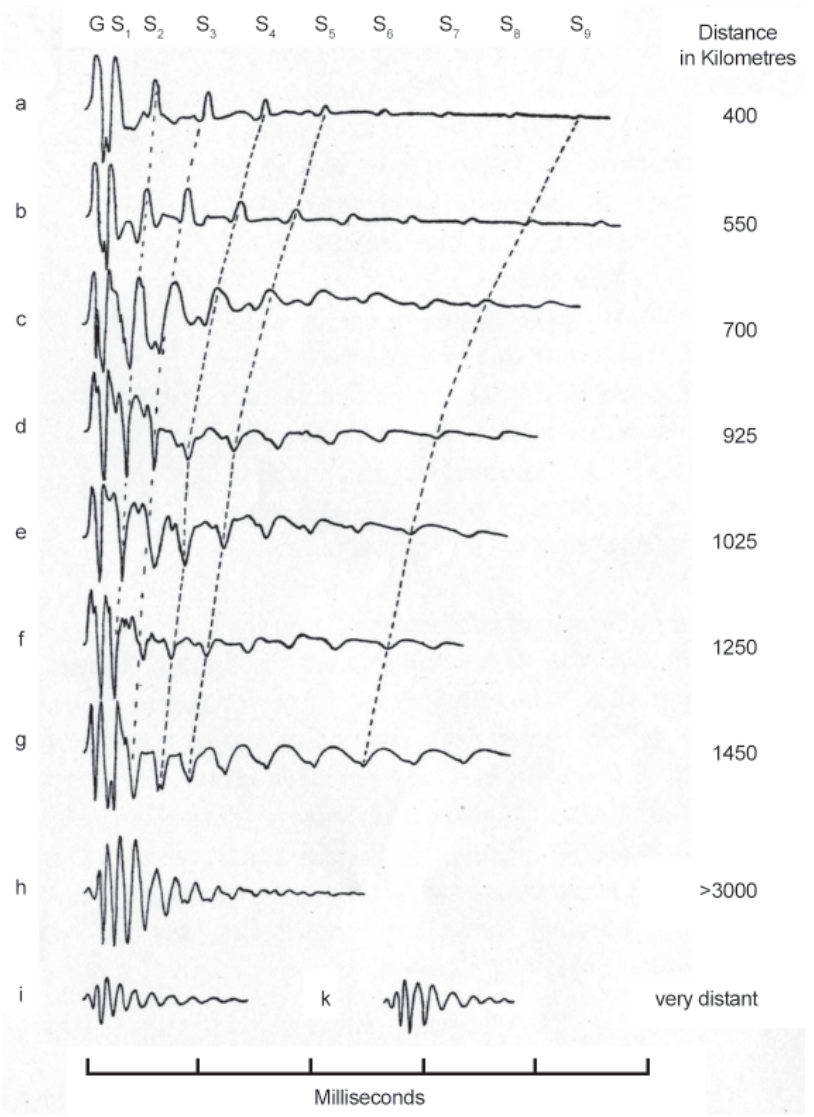

Fig. 12. The change of waveforms with propagation distance. The waveform of ionospheric reflection type changes its waveform to quasi-sinusoidal type with propagation distance (Schonland et al. 1940).

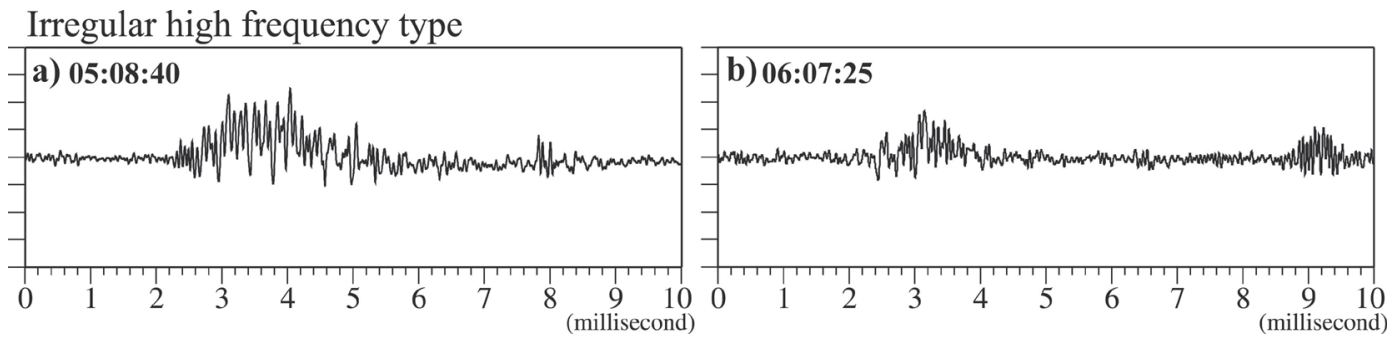

Fig. 13. The waveforms of irregular high frequency type. The baseline of these waves fluctuates irregularly during $1-5$ milliseconds. The frequency is about $10 \mathrm{kHz}$. 
was observed intermittently when the lightning activity was high. The waves of the irregular high frequency type are considered as originating from lightning activities such as leader strokes and discharges in the clouds (Sao 1981).

Artificial noise: Large pulses appear at regular intervals of 16.67 milliseconds which is the cycle time of $60 \mathrm{~Hz}$. Each pulse attenuates without vibration. Although most of this type was too small to trigger the recorder, some pulses had amplitude large enough to trigger it. This happened many times during our five hour observation. Waves of this type were most likely generated by nearby artificial sources.

Other type (Fig. 14): Figure 14 shows the large fluctuations observed when the seismic $\mathrm{S}$ wave arrived at the observation station. The electromagnetic waves which exceeded the threshold were observed 80 or more times in 10 seconds following the $S$ wave arrival. Figure 14b is the enlargement of the head portion of these fluctuations. Figure $14 \mathrm{c}$ is the enlargement of the portion A of Fig. 14b. Their waveforms were very unique and not similar to any other types. These waveforms have many more pulses and contain much higher frequencies than the $\mathrm{S}$ wave. Since these waveforms were never observed even if we shook the antenna and observation system, these waves were not generated by shaking due to the $\mathrm{S}$ wave. Although there was a large aftershock $\left(\mathrm{M}_{\mathrm{J}}\right.$ 5.4) at 07:38 and many other aftershocks during the five hour observation, waves of this type were not observed at the times of any aftershocks. The reason for this behavior is unknown. Electromagnetic changes accompanying seismic waves are reported by other observations (Iyemori et al. 1996; Nagao et al. 2000; Honkura et al. 2000, 2002). These changes can be considered as induced by ground tremors or the piezoelectric effect near the observation station. However, the behavior we observed is difficult to explain by the same mechanism and the possibility that the waves we observed were noises emitted from the destruction of electric appliances and electric power failure induced by the main shock cannot be excluded. At the origin time of the earthquake, 05:46:51, no remarkable signals were recorded.

Artificial noise excluded, a total of 417 waveforms recorded during the five hours of observation is classified as follows:

82 waveforms simultaneous with $\mathrm{S}$ wave arrival,

80 ionospheric reflection types,

8 quasi-sinusoidal types,

49 slow tail types,

114 intermediate types, and

84 irregular high frequency types.

Figure 15 is the histogram of the occurrences of each type. Between 04:50 and 10:03 on January 17, lightning activities in Shimane Prefecture and off the coast of Kochi Prefecture were reported. The time of the lightning activity is depicted at the uppermost part of the figure. Many waveforms were recorded when lightning activities were reported, but some waveforms were not.

By identifying the reported times of lightning, 23 pulses were correlated with well located lightning with certainty. Of these pulses, 9 were from Kochi Prefecture and 14 were from Shimane 
Prefecture (Fig. 16). The distance to the observation station was nearly the same (280 km from Kochi and $320 \mathrm{~km}$ from Shimane Prefectures).

There were many more lightning strikes with unidentified locations in the lightning data. Comparing the times of such un-located lightning and recorded electromagnetic pulses, we

a) Fluctuations recorded with $S$ wave $(05: 47: 00$ - 05:47:30)

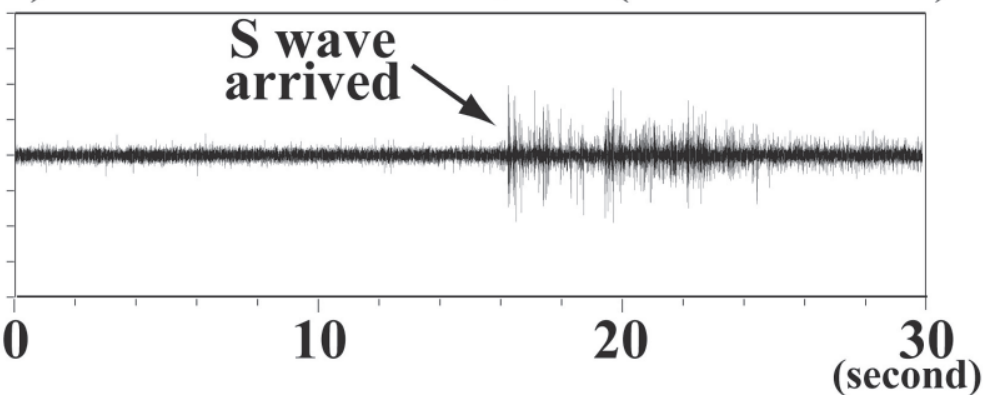

b) The head waveforms of the fluctuations recorded with $\mathrm{S}$ wave

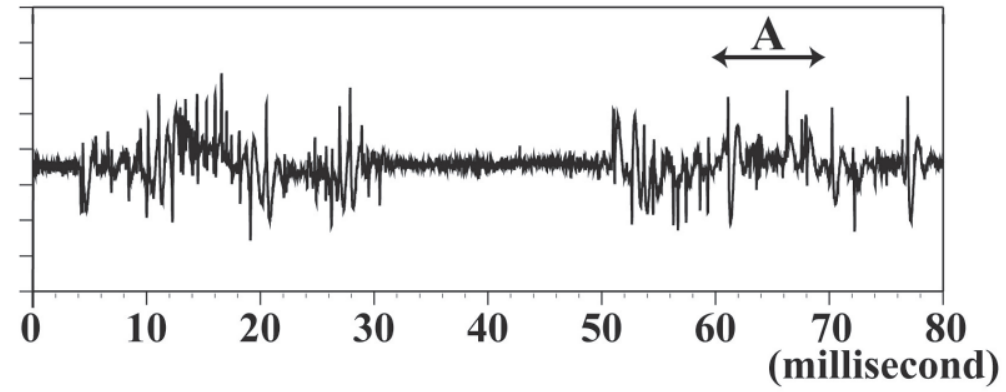

c) The enlargement of the period A in Fig.14b

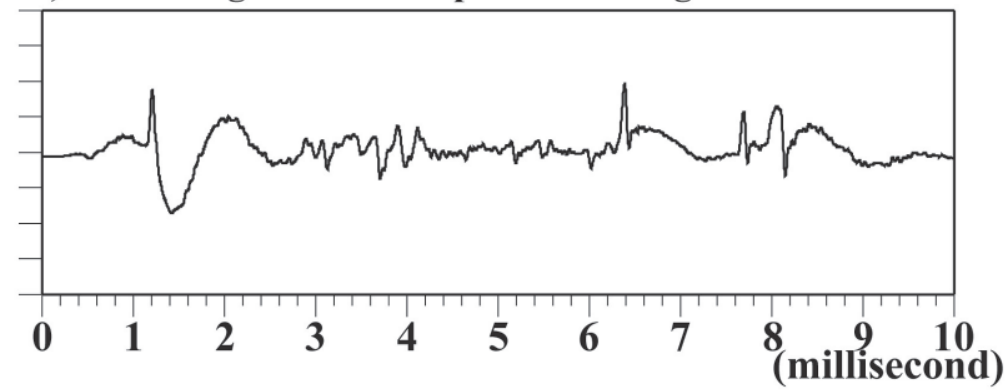

Fig. 14. (a) The large fluctuations observed at 05:47:16, i.e., the time when the $\mathrm{S}$ wave arrived at the observation station. 82 irregular pulses triggered the recording system continuously during about 10 seconds. (b) The head portion of the large fluctuations recorded at the time of $S$ wave arrival. (c) The enlargement of the period A of Fig. 14b. These waveforms resembled no other types. 


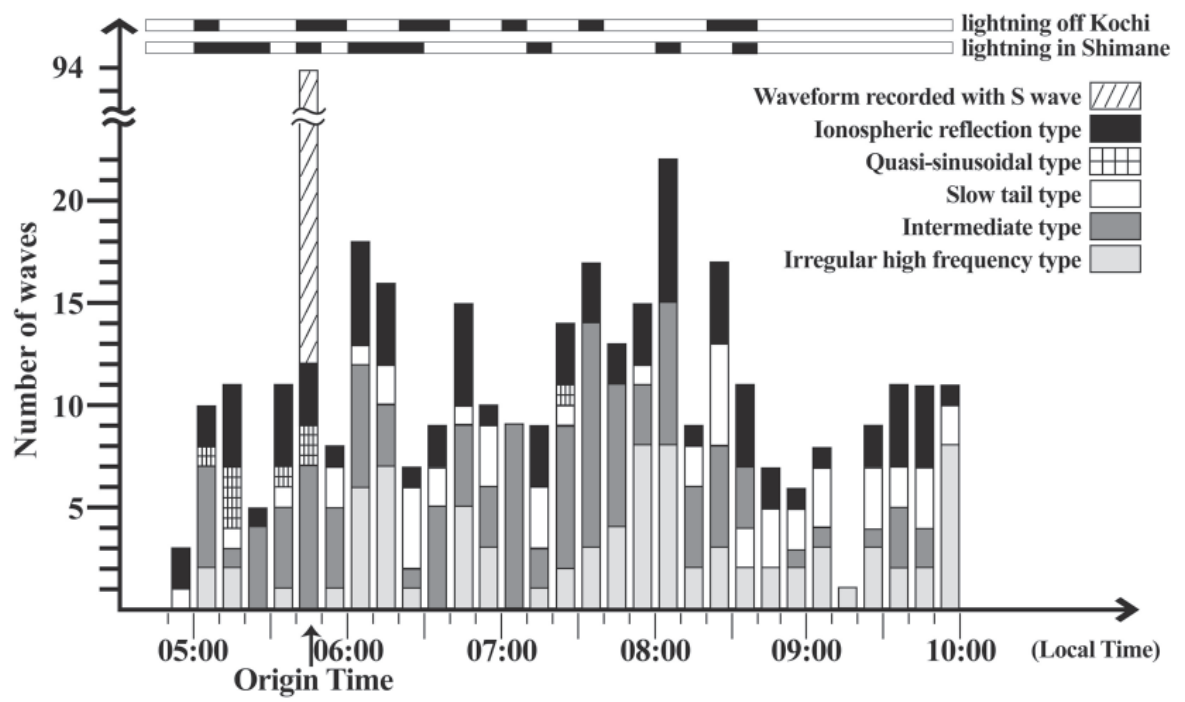

Fig. 15. The histogram of each type. Artificial noises are excluded. The periods of the lightning activity are shown by black bars above the histogram.

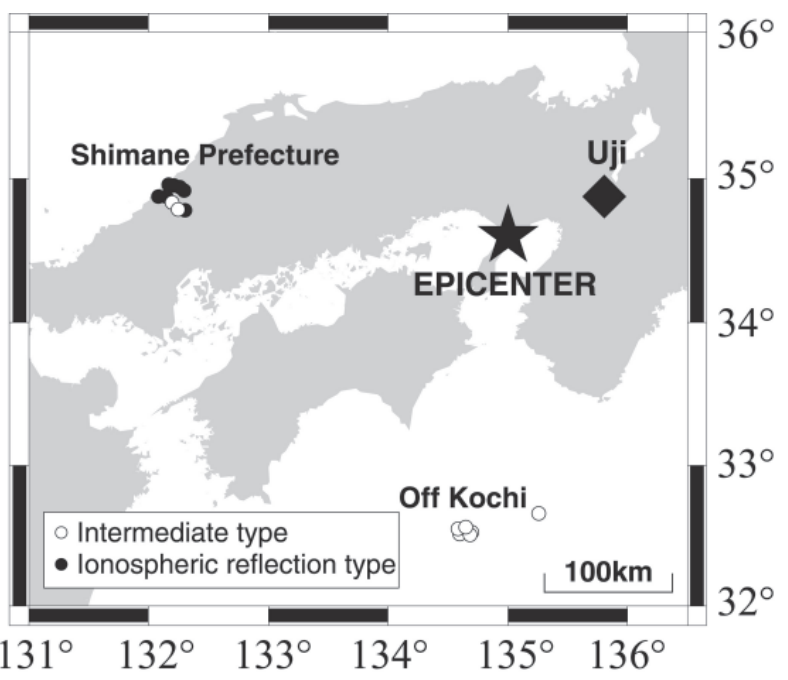

Fig. 16. The map for the locations of the lightning and observation station. Some lightning struck off the coast of Kochi and in Shimane Prefecture, generating pulses with waveforms of the ionospheric reflection type and the intermediate type. 
found 131 pulses correspond to un-located lightning. The waveforms of these pulses were ionospheric reflection type, slow tail type and intermediate type. As shown above, the total number of ionospheric reflection type, slow tail type and intermediate type waves was 243. Therefore, a half of these pulses can be considered as lightning in origin. The other half were not correlatable with lightning data. However, as stated above, the lightning data of the electric power companies did not cover all the concerned region and did not contain all the lightning. Therefore, many observed pulses of similar waveform could have been generated by un-located lightning.

Yamada and Oike (1999) suggested a possibility that there were seismic electromagnetic waveforms occurring just before the 1995 Hyogo-ken Nanbu earthquake. However, as a result of the present inspection, this possibility appears to be questionable: The quasi-sinusoidal type waveform, propagated from $3000 \mathrm{~km}$ or more, could not be related to the earthquake. The ionospheric reflection type, slow tail type, intermediate type, and irregular high frequency type waveforms were found to have been generated by lightning activities in Shimane Prefecture, Kochi Prefecture and other places far from the epicenter. The pulses observed at the $\mathrm{S}$ wave arrival time were considered to be generated near the observation station. Considering the results of the present analysis, it seems most probable that we caught no seismic electromagnetic signal from the epicenter just before the earthquake, and the increase in the number of pulses was caused by the lightning activities elsewhere.

\subsection{Other Earthquakes}

In section 3, the relationship between the increase in the number of the electromagnetic pulses and lightning was investigated. It was found that both the lightning within $200-300 \mathrm{~km}$ of the observation station, and the more distant lightning with large amplitude generate observable electromagnetic pulses. Actually, in past reports, a striking possibility has been postulated that the lightning was the cause of the increase in the number of the electromagnetic pulses before and after earthquakes (Oike et al. 1993; Yamada and Oike 1999).

In both Figs. 2 and 5, an increase in the number of the LF pulses is seen before an earthquake and also seen after an earthquake. It seems that they both have 5- to 8-day cycles. The cycle of the high and low atmospheric pressures is also about one week. Therefore, there is a possibility that the recorded increase of the pulses was solely caused by thunderbolt activities accompanying the passage of low atmospheric pressure.

Since the lightning location system was not established in the 1980s, thunderbolt activity in a wide area from western Japan to mid Japan was investigated only through the publications of the Japan Meteorological Agency [Japan Meteorological Agency (1983 - 2002)]. For example, in the case of the 12 July 1993 Hokkaido-Nansei-Oki earthquake $\left(\mathrm{M}_{\mathrm{J}} 7.8\right)$ [See Fig.13 in Oike and Yamada (1994)], a low pressure system passed through the Sea of Japan and the front stagnated on July 9. There were thick fog, heavy rain, and lightning in the area of the Sea of Japan's coast from July 10 to 15 (two days before and three days after the earthquake) when the increase was observed.

As a result of investigating all these cases, it became clear that rainfall and lightning were almost always reported in the area from western Japan to mid Japan when the number of 
pulses increased. We could not find any case where such an increase was observed before and after earthquakes without thunderbolt activity.

Of course, it cannot be said that all increases in the number of pulses were caused by lightning, but it can be said that almost all of them are caused by lightning. Even if there were seismic electromagnetic signals in our observation data, it has been difficult to demonstrate its existence convincingly probably because they were much smaller than the effects of the lightning.

\subsection{Score of the Past Observation}

In Oike and Murakami (1993), a remarkable increase in the number of LF pulses was observed in 7 out of 10 earthquakes as mentioned previously. However, the "remarkable increase" was not clearly defined by them. Therefore, we introduced an objective criterion and examined the possibility of applying this observation system to short-term earthquake forecasting.

We defined the anomaly as the "case when the number of LF pulses exceeded the average by more than $2 \sigma$ ", where $\left(\sigma^{2}\right)$ is the variance. However, the average as well as the variance of lightning changes with local time and season, so that a reference state had to be obtained for each hour of the day of each month using the whole period of observation, i.e., 14 years from 1983 to 1996.

As a result of being able to judge the anomaly on a monthly and hourly basis, strong seasonal and hourly dependence are clearly seen. The target earthquakes are shallow (30-km or less) earthquakes with $\mathrm{M}$ equal to or larger than 6 which have epicenters inland or beneath shallow seas of water depth $1000 \mathrm{~m}$ or less near Japan. The epicenters of which are near the Uji station $\left(32-38^{\circ} \mathrm{N}, 134-142^{\circ} \mathrm{E}\right)$ during the period from January, 1983 to March, 1996. There were 68 such earthquakes. Among them, 22 earthquakes showed the above defined anomalies within 48 hours before earthquakes. The hit rate (the ratio of earthquakes with the anomalies to all earthquakes) is 22/68. However, there were 771 anomalies (successive anomalies are counted as 1 anomaly). Therefore, if an alarm is issued on each anomaly, the success rate (the ratio of earthquakes with anomaly to the anomalies) would be $22 / 771$. This ratio is obviously too low for any practical forecasting. The 771 anomalies over approximately 14 years mean that there was about one anomaly every week. This once per week cycle seems to be coincident with the cycle of the passage of low atmospheric pressure as mentioned in the previous section. The 22 out of 68 earthquakes occurred within 48 hours after an anomaly. However, these anomalies occurred almost every week so that if an earthquake occurred randomly, the probability of an earthquake occurring within 48 hours ( 2 days) after an anomaly is $2 / 7$ (0.2857), which is close to $22 / 68(0.3235)$. Thus, the results of this observation were not significant from the viewpoint of earthquake forecasting.

\section{DISCUSSION}

We have quantitatively shown that most of the increases in the number of LF and VLF electromagnetic pulses are generated by lightning. Although all the recorded electromagnetic 
pulses have not been identified with lightning, it has been shown that the influence of lightning is almost exclusive at least in the LF and VLF ranges.

In the case of other studies, i.e., studies in the different frequency ranges, we can also point out the possible importance of the influence of lightning. Possible seismic electromagnetic signals were reportedly observed on 9 January 1995, eight days before the 1995 Hyogo-ken Nanbu earthquake. However, Yamada and Oike (1999) and Nagao et al. (2002) suggested that the possible influence of lightning on some of these observations cannot be ruled out with confidence. This study shows that their suggestion was correct as far as LF- and VLF-pulse observation is concerned. Possible seismic electromagnetic signals 50 minutes before the Hyogo-ken Nanbu earthquake were observed by Fujinawa and Takahashi (1995), Maeda and Tokimasa (1996), and Hata (1997). Hata (1997) observed a three-component geomagnetic field at a frequency of $223 \mathrm{~Hz}$ at Usami in Izu. Fujinawa and Takahashi (1995) observed a variation in the underground electric field at $1-9 \mathrm{kHz}$ by using the casing pipes of boreholes as antennas at Hasaki in Ibaragi Prefecture. Both Usami and Hasaki are more than $400 \mathrm{~km}$ east of the epicenter and $700 \mathrm{~km}$ from Shimane and Kochi Prefectures. It is doubtful if these observations made so far away from Shimane and Kochi Prefectures were heavily influenced by the same lightning activities. It is equally or even more doubtful if the supposedly much weaker seismic signals were observed at these places. During their observation of electromagnetic waves from the Planet Jupiter by a radio interferometer, Maeda and Tokimasa observed anomalous $22.2 \mathrm{MHz}$ waves at Nishi-Harima Astronomical Observatory located at distance of $77 \mathrm{~km}$ from the epicenter. The Observatory was even closer than Uji to the lightning activities in Shimane Prefecture and off Kochi Prefecture. However, they found that the anomalous signals probably came from the direction of the fault that caused the earthquake, there is a possibility that their system using an interferometer in the $\mathrm{MHz}$ range could have been more immune to lightning.

Yoshino (1997) reported a continuous increase in the noise level of MF radio broadcast near the epicenter just before the 1995 Hyogo-ken Nanbu earthquake. Hayakawa et al. (1996) and Kushida and Kushida $(1998,2002)$ reported the anomaly of electromagnetic wave propagation before the Hyogo-ken Nanbu earthquake at a frequency of VLF and VHF, respectively. These anomalies are hard to explain by lightning. These propagation anomalies would affect our observation system as a change of a variance reduction between the observed pulses and lightning which we calculate in section 3.2. However, we cannot discuss these directly because of our approximate calculation of variance reduction and the quality of lightning data at that time.

Now, which frequency range is best to find seismic electromagnetic wave signals?

The intensity of the electric field generated by lightning is largest in the VLF range at a distance of $10 \mathrm{~km}$ from lightning location, and decreases with increasing frequency. The signalto-noise ratio is lowered by the noise generated by lightning in VLF and LF ranges. In the observation of the number of electromagnetic pulses, we can estimate the number of noises generated by lightning by using the method described in section 3 . However, we cannot know the exact location and lightning currents of all lightning. Cloud-to-cloud discharge and leader strokes which are not recorded in the lightning data also affect observations. The complete 
removal of the influence of lightning is impossible at present and thus the observations in VLF and LF ranges are not very suitable for earthquake forecasting purposes.

Recently, to remove the influence of lightning, Asada et al. (2001) and Tsutsui (2005) adopted direction search and identification by waveform. They reported the possibility of the existence of VLF pulses transmitting from an epicenter before an earthquake. Observation in the VLF range is very important and should be continued regardless of the effort required.

Moreover, electromagnetic waves in radio interferometer VHF ranges are not reflected by the ionosphere and do not propagate at large distances. Thus, the influence of far lightning becomes smaller with frequency, suggesting that observation in the VHF range may be more suitable from the viewpoint of mitigating the influence of lightning. Artificial noises also need to be considered. In high frequency ranges, there are influences from electromagnetic waves for broadcasting and communication. By choosing a proper observation frequency, we may be able to minimize the influence of such artificial noise.

However, absorption in the earth of electromagnetic waves increases with frequency. High frequency electromagnetic waves cannot be expected to rise to the surface from deep underground. Therefore, a lower frequency range is favorable to observe seismic electromagnetic wave signals generated underground albeit that the higher frequency range is more favorable for avoiding lightning noise. These are conflicting factors.

Although observations of seismic electromagnetic wave signals have been made using various methods and various frequency ranges, the calibration between different observation systems and comparison of results have not been carried out sufficiently. A well coordinated simultaneous broad-band observation in a dense network covering a wide-area together with a much improved lightning location system should be the key to raising seismo-electromagnetic science to a convincing level.

As a result of this analysis, we found most of the increases in the number of LF and VLF electromagnetic pulses before earthquakes were generated by lightning. Be that as it may, it seems that there is some relationship between weather (lightning) and earthquakes. Recently, some research has been performed about the relationship between lightning and earthquakes (Ouzounov et al. 2000). Avagimov et al. (2004) reported that high-energy electromagnetic pulses emitted by a magneto-hydrodynamic (MHD) generator influenced the seismicity in the area of northern Tien Shan. This work suggested that the large current triggered earthquakes.

There was no lightning location data when the observations started and lightning data has improved. Now we can reference lightning data around Japan by a proper lightning detection system. Oike and Yamada (1994) mentioned that the number of electromagnetic pulses would increase if an earthquake triggers lightning or lightning triggers an earthquake. Evidently, it is still necessary to pursue further study about the relationship between the lightning and earthquakes.

\section{CONCLUSIONS}

We have investigated the influence of lightning on the observation of electromagnetic pulses in this thesis. The main results of this study are: 
(1) A close statistical relationship between observed electromagnetic pulses and lightning has been established by using the number of the electromagnetic pulses observed by our Tokai observation network and the lightning data provided by the Japan Lightning Detection Network.

(2) Lightning activity within about $250 \mathrm{~km}$ in the LF range and about $420 \mathrm{~km}$ in the VLF range were the major sources of pulses observed by our measuring system.

(3) For increased electromagnetic pulses just before the 1995 Hyogo-ken Nanbu earthquake, the continuous VLF waveforms recorded from 50 minutes before the earthquake indicated that most of the waveforms were generated by lightning. For other earthquakes also, the increase in the number of electromagnetic pulses may be considered as due to lightning because the passage of low atmospheric pressure and lightning activities were reported within a distance of about $250 \mathrm{~km}$ from the observation station almost always when the increase was observed. Even if the seismic electromagnetic signals really existed, they would have been much weaker than those of lightning and difficult to identify (e.g., Asada et al. 2001).

(4) The results of the electromagnetic observation at our Uji station have been re-examined from the viewpoint of earthquake forecasting. The success rate is very low and hit rate is not significant and thus the application of our observation in the VLF and LF ranges to short-term earthquake forecasting cannot be considered promising.

(5) Broad-band and wide-area observations, with thorough monitoring of lightning, should be attempted in future electromagnetic study for earthquake forecasting.

Acknowledgements This study was done as a part of the RIKEN International Frontier Research Program on Earthquake. I am very grateful to Seiya Uyeda (Research Leader of IFREQ), Toshiyasu Nagao and many RIKEN staff for their great help, comments, and encouragement. I would like to express very deep gratitude to reviewers for their suggestions and comments improving this paper. I am very grateful to Franklin Japan Corporation and the Shikoku, Chugoku, Kansai and Chubu Electric Power Companies for the lightning data. This work is partially supported by a Grant from the Ministry of Education, Culture, Sports, Science, and Technology to promote multidisciplinary research projects (in 2006 - 2010).

\section{REFERENCES}

Asada, T., H. Baba, M. Kawazoe, and M. Sugiura, 2001: An attempt to delinate very low frequency electromagnetic signals associated with earthquakes. Earth Planets Space, 53, 55-62.

Avagimov, A., L. Bogomolov, T. Cheidze T. A. Ponomarev, G. Sobolev, N. Tarasov, and V. Zeigarnik, 2004: Induced seismicity by trigger stimulation from laboratory and field tests. The Proceedings of IWAM04 (International Workshop on "Active Monitoring in the Solid Earth Geophysics"), S2-06.

Cress, G. O., B. T. Brady, and G. A. Rowell, 1987: Sources of electromagnetic radiation from fracture of rock samples in the laboratory. Geophys. Res. Lett., 14, 331-334. 
Enomoto, Y., A. Tsutsumi, Y. Fujinawa, M. Kasahara, and H. Hashimoto, 1997: Candidate precursors: Pulse-like geoelectric signals possibly related to recent seismic activity in Japan. Geophys. J. Int., 131, 485-494.

Fraser-Smith, A. C., A. Bernardi, P. R. McGill, M. E. Ladd, R. A. Helliwell, and O. G. Villard, Jr., 1990: Low-frequency magnetic field measurements near the epicenter of the $M_{s} 7.1$ Loma Prieta earthquake. Geophys. Res. Lett., 17, 1465-1468.

Fujinawa, Y., and K. Takahashi, 1995: Characteristics of electric field variations before and after the 1995 Hyogo-ken Nanbu earthquake. Chikyu Monthly, 13 (Special Issue), 175184. (in Japanese)

Gokhberg, M. B., V. A. Morgounov, and E. L. Arnov, 1979: On high frequency electromagnetic radiation during seismic activity. Dok. Acad. Nauk SSSR, 248, 1077.

Gokhberg, M. B., V. A. Morgounov, T. Yoshino, and I. Tomizawa, 1982: Experimental measurement of electromagnetic emissions possibly related to earthquakes in Japan. $J$. Geophys. Res., 87, 7824-7828.

Hata, M., 1997: Can we catch precursor of inland earthquake through extremely low frequency electromagnetic wave? Proceedings of 1997 Conductivity Anomaly Meeting, 59-66. (in Japanese)

Hattori, K., 2004: ULF geomagnetic changes associated with large earthquakes. Terr. Atmos. Ocean. Sci., 15, 329-360.

Hayakawa, M., O. A. Molchanov, T. Ondoh, and E. Kawai, 1996: Anomalies in the subionospheric VLF signals for the 1995 Hyogo-ken Nanbu earthquake. J. Phys. Earth, 44, 413-418.

Hepburn, F., 1957: Wave-guide interpretation of atmospheric waveforms. J. Atmos. Terr. Phys., 10, 121-135.

Honkura, Y., A. M. Ishikara, N. Oshiman, A. Ito, B. Ucer, S. Baris, M. K. Tuncer, M. Matsushima, R. Pektas, C. Celik, S. B. Tank, F. Takahashi, M. Nakanishi, R. Yoshimura, Y. Ikeda, and T. Komut, 2000: Preliminary results of multidisciplinary observations before, during and after the Kocaeli (Izmit) earthquake in the western part of the North Anatolian Fault Zone. Earth Planets Space, 52, 293-298.

Honkura, Y., M. Matsushima, N. Oshiman, M. K. Tuncer, S. Baris, A. Ito, and A. M. Isikara, 2002: Small electric and magnetic signals observed before the arrival of seismic wave. Earth Planets Space, 54, e9-e12.

Ishido, T., and H. Mizutani, 1981: Experimental and theoretical basis of electrokinetic phenomena in rock-water systems and its applications to geophysics. J. Geophys. Res., 86, 1763-1775.

Ishii, M., F. Fujii, T. Shimohori, M. Saito, A. Sugita, and S. Hidayat, 2001: Detection efficiency of JLDN. Proc. 12 ${ }^{\text {th }}$ Ann. Confer. PE Soc. IEEJ Vol. B, 191-192. (in Japanese)

Iyemori, T., T. Kamei, Y. Tanaka, M. Hashimoto, T. Araki, T. Okamoto, K. Watanabe, N. Sumitomo, and N. Oshiman, 1996: Co-seismic geomagnetic variations observed at the 1995 Hyogoken-Nanbu earthquake. J. Geomag. Geoelectr., 48, 1059-1070.

Izutsu, J., and K. Oike, 2003: The waveforms of VLF electromagnetic waves recorded at the time of the 1995 Hyogo-ken Nanbu earthquake. Proc. Japan Acad. Ser. B, 79, 125130. 
Japan Meteorological Agency, 1983 - 2002: Geophysical Review. Japan Meteorological Agency. (in Japanese)

Kimpara, A., 1956: The waveform of atmospherics in the daytime and at night. Proc. Res. Inst. Atmos. Nagoya Univ., 4, 1-19.

Kopytenko, Y., T. G. Matiashvili, P. M. Voronov, E. A. Kopytenko, and O. A. Molchanov, 1993: Detection of ultra-low-frequency emissions connected with the Spitak earthquake and its aftershock activity, based on geomagnetic pulsations data at Dusheti and Vardzia observatories. Phys. Earth Planet. Inter., 77, 85-95.

Kushida, Y., and R. Kushida, 1998: On the possibility of earthquake forecast by radio observation in the VHF band. RIKEN Review, 19, 152-160.

Kushida, Y., and R. Kushida, 2002: Possibility of earthquake forecast by radio observations in the VHF band. J. Atmos. Electr., 22, 239-255.

Maeda, K., and N. Tokimasa, 1996: Decametric radiation at the time of the Hyogo-ken Nanbu earthquake near Kobe in 1995. Geophys. Res. Lett., 23, 2433-2436.

Maki, K., and T. Ogawa, 1983: ELF emissions associated with earthquakes. Res. Lett. Atmos. Electr., 3, 41-44.

Molchanov, O., A. Yu., A. Kopytenko, P. M. Voronov, E. A. Kopytenko, T. G. Matiashvili, A. C. Fraser-Smith, and A. Bernardi, 1992: Results of ULF magnetic field measurements near the epicenters of the Spitak $\left(M_{s}=6.9\right)$ and Loma Prieta $\left(M_{s}=7.1\right)$ earthquakes: Comparative analysis. Geophys. Res. Lett., 19, 1495-1498.

Nagao, T., Y. Orihara, T. Yamaguchi, I. Takahashi, K. Hattori, Y. Noda, K. Sayanagi, and S. Uyeda, 2000: Co-seismic geoelectric potential changes observed in Japan. Geophys. Res. Lett., 27, 1535-1538.

Nagao, T., Y. Enomoto, Y. Fujinawa, M. Hata, M. Hayakawa, Q. Huang, J. Izutsu, Y. Kushida, K. Maeda, K. Oike, S. Uyeda, and T. Yoshino, 2002: Electromagnetic anomalies associated with 1995 Kobe earthquake. J. Geodyn., 33, 401-411.

Nitsan, U., 1977: Electromagnetic emission accompanying fracture of quartz-bearing rocks. Geophys. Res. Lett., 4, 333-336.

Ogawa, T., Y. Tanaka, T. Miura, and M. Yasuhara, 1966: Observations of natural ELF and VLF electromagnetic noises by using ball antennas. J. Geomag. Geoelectr., 18, 443454.

Ogawa, T., and Y. Tanaka, 1970: Effective height of the ball antenna for measuring ELF radio signals. Spec. Contribut., Geophys. Inst., Kyoto Univ., 10, 29-34.

Ogawa, T., 1973: Analyses of measurement techniques of electric fields and currents in the atmosphere. Spec. Contribut., Geophys. Inst., Kyoto Univ., 13, 111-137.

Ogawa, T., K. Oike, and T. Miura, 1985: Electromagnetic radiations from rocks. J. Geophys. Res., 90, 6245-6249.

Oike, K., and T. Ogawa, 1986: Electromagnetic radiations from shallow earthquakes observed in the LF range. J. Geomag. Geoelectr., 38, 1031-1040.

Oike, K., and H. Murakami, 1993: On the relationship between shallow earthquakes and LF and VLF noises. Tech. note Nat. Res. Inst. Earth Sci. Disast. Prev., 157, 221-251. (in Japanese)

Oike, K., H. Murakami, and T. Nagai, 1993: On the relationship between shallow earthquakes 
and lightnings. Tech. note Nat. Res. Inst. Earth Sci. Disast.Prev., 157, 253-272. (in Japanese)

Oike, K., and T. Yamada, 1994: Relationship between shallow earthquakes and electromagnetic noises in the LF and VLF ranges. In: Hayakawa, M., and Y. Fujinawa (Eds.), Electromagnetic Phenomena Related to Earthquake Prediction, Terrapub, Tokyo, 115130.

Ouzounov, D., R. Williams, and R. Wohlman, 2000: A joint analysis of earthquake and lightning activity in the southern California. Programme and Abstracts of International Workshop on Seismo Electromagnetics of NASDA, 2000, Tokyo, 136.

Sao, K., 1981: Atmospheric Electricity. Seizando Shoten, Japan. (in Japanese)

Schonland, B. F. J., J. S. Elder, D. B. Hodges, W. E. Phillips, and J. W. van Wyk, 1940: The wave form of atmospherics at night. Proc. Roy. Soc. London Ser. A, 176, 180-202.

Shindo, T., 1998: Lightning location systems in power utilities, The Papers of Technical Meeting on High Voltage IEE Japan, HV-98-22, 41-46. (in Japanese)

Tsutsui, M., 2005: Identification of earthquake epicenter from measurements of electromagnetic pulses in the Earth. Geophys. Res. Lett., 32, L20303,10.1029/2005GL023691.

Uyeda, S., T. Nagao, Y. Orihara, T. Yamaguchi, and I. Takahashi, 2000: Geoelectric potential changes: Possible precursors to earthquakes in Japan. Proc. Natn. Acad. Sci., 97, 45614566.

Uyeda, S., M. Hayakawa, T. Nagao, O. Molchanov, K. Hattori, Y. Orihara, K. Gotoh, Y. Akinaga, and H. Tanaka, 2002: Electric and magnetic phenomena observed before the volcano-seismic activity in 2000 in the Izu Island Region, Japan. Proc. Natn. Acad. Sci., 99, 7352-7355.

Uyeda, S., T. Nagao, and H. Tanaka, 2004: A report from the RIKEN International Frontier Research Project on Earthquake (IFREQ). Terr. Atmos. Ocean. Sci., 15, 269-310.

Varotsos, P., and K. Alexopoulos, 1984a: Physical properties of the variations of the electric field of the Earth preceding earthquakes, I. Tectonophysics, 110, 73-98.

Varotsos, P., and K. Alexopoulos, 1984b: Physical properties of the variations of the electric field of the Earth preceding earthquakes, II, Determination of epicenter and magnitude. Tectonophysics, 110, 99-125.

Wait, J. R., 1970: Electromagnetic Waves in Stratified Media. $2^{\text {nd }}$ edition, Pergamon Press Ltd., Oxford.

Warwick, J. W., C. Stoker, and T. R. Meyer, 1982: Radio emission associated with rock fracture: Possible application to the great Chilean earthquake of May 22, 1960. J. Geophys. Res., 87, 2851-2859.

Yamada, T., and K. Oike, 1996: Electromagnetic radiation phenomena before and after the 1995 Hyogo-ken Nanbu Earthquake. J. Phys. Earth, 44, 405-412.

Yamada, T., 1998: Study on increase of electromagnetic noises before and after the 1995 Hyogo-ken Nanbu earthquake. Ph.D. Thesis, Kyoto University.

Yamada, T., and K. Oike, 1999: On the increase of electromagnetic noises before and after the 1995 Hyogo-ken Nanbu earthquake. In: Hayakawa, M. (Ed.), Atmospheric and Ionospheric Electromagnetic Phenomena Associated with Earthquakes, Terrapub, Tokyo, 417-427. 
Yoshida, S., M. Uyesima, and M. Nakatani, 1997: Electric potential changes associated with slip failure of granite: Preseismic and coseismic signals. J. Geophys. Res., 102, 1488314897.

Yoshida, S., and T. Ogawa, 2004: Electromagnetic emissions from dry and wet granite associated with acoustic emissions. J. Geophys. Res., 109, B09204, doi:10.1029/2004JB 003092.

Yoshino, T., I. Tomizawa, and T. Shibata, 1985: The possibility of using a direction finding technique to locate earthquake epicenters from electromagnetic precursor radiation. Ann. Geophys., 3, 727-730.

Yoshino, T., 1997: The study of the generation mechanism of preseismic radiation of EM fields and EM wave at focus, epicenter and ionospheric area in the higher frequency band than VLF. Proceedings of 1997 Conductivity Anomaly Meeting, 82 - 89. (in Japanese)

Izutsu, J., 2007: Influence of lightning on the observation of seismic electromagnetic wave anomalies. Terr. Atmos. Ocean. Sci., 18, 923-950, doi: 10.3319/TAO.2007.18.5.923(T). 